\title{
ROLE OF EVALUATING EXERCISE CAPACITY AND DLCO IN APPARENTLY HEALTHY STONE WORKERS IN AGRA- A CASE CONTROL STUDY
}

\author{
Santosh Kumar1, Sanjeev Anand², Gajendra Vikram Singh'3 , Benhur Joel Shadrach4, Rishabh Goel5, Parul Mittal6, Avinash Kumar7, \\ Chandrakant Kachru Khandare 8
}

\author{
${ }^{1}$ Associate Professor and Head, Department of Tuberculosis and Chest Diseases, S. N. Medical College, Agra \\ ${ }^{2}$ Ex-Senior Resident, Department of Tuberculosis and Chest Diseases, S. N. Medical College, Agra. \\ ${ }_{3}^{3}$ Associate Professor, Department of Tuberculosis and Chest Diseases, S. N. Medical College, Agra. \\ 4 Junior Resident, Department of Tuberculosis and Chest Diseases, S. N. Medical College, Agra. \\ 5Junior Resident, Department of Tuberculosis and Chest Diseases, S. N. Medical College, Agra. \\ 6Junior Resident, Department of Tuberculosis and Chest Diseases, S. N. Medical College, Agra. \\ 7Junior Resident, Department of Tuberculosis and Chest Diseases, S. N. Medical College, Agra. \\ 8Junior Resident, Department of Tuberculosis and Chest Diseases, S. N. Medical College, Agra.
}

\section{BACKGROUND}

\section{ABSTRACT}

Occupational Lung diseases are on the rise and contribute to the burden of lung disease. Worldwide, silicosis is the most common occupational lung disease. Exposure includes stone cutting, quarrying, rock blasting, pottery, foundry and sandblasting. Silicosis is caused by inhalation of crystalline silica quartz (silica dioxide) leading to inflammation, scarring and eventually lung fibrosis and destruction.

Aims and Objectives- Evaluation of exercise capacity (6MWT) and diffusion study in apparently healthy stone workers in Agra and to assess the role of exercise tolerance and diffusion capacity in early detection of occupational lung disease and prognosis.

\section{MATERIALS AND METHODS}

This is a descriptive comparative study. We evaluated 54 patients who were apparently healthy and had occupational exposure as stone workers, among which 24 were excluded due to previous tuberculosis and other lung diseases. It was a case control study between exposed workers and unexposed healthy persons. Evaluation included detailed history and clinical examination, CXR, Spirometry including DLCO, Exercise performance assessment (6MWT) and $\mathrm{Sp}_{2}$ at rest.

\section{RESULTS}

30 Cases and 28 Controls were included in the study. They were sub divided further on the basis of age, sex, duration of exposure, respiratory rate, oxygen saturation, pulmonary function testing including DLCO and 6MWT. Mean DLCO in cases was 25.4812 and in controls was 28.6371 (p-0.0452). The 6MWT in cases was 476.32 and controls was 540.4643 (p-0.0436). Spirometry showed restrictive pattern in 8 patients, mixed pattern in 2 patients and was normal in 20 patients. The mean $\mathrm{SpO}_{2}$ was $94.633 \%$ in cases and $94.642 \%$ in controls.

\section{CONCLUSION}

The study shows that in apparently healthy cases of silica workers, the earliest indicator of disease is the reduction of DLCO. Also, the exercise capacity is significantly reduced in these patients. (Though spirometry was normal in more than half of these cases). These 2 parameters help in early disease identification and allow for prevention of exposure, stop disease progression and alter the final course of illness and decrease significant morbidity and possible mortality.

\section{KEYWORDS}

Exercise Capacity, Diffusion Study, Stone Workers, Spirometry.

HOW TO CITE THIS ARTICLE: Kumar S, Anand S, Singh GV, et al. Role of evaluating exercise capacity and DLCO in apparently healthy stone workers in Agra- a case control study. J. Evolution Med. Dent. Sci. 2018;7(08):998-1001, D0I: $10.14260 /$ jemds/2018/228

\section{BACKGROUND}

Occupational exposures play an important role in many diseases. Hazardous exposure in the work place and elsewhere in environment continue to contribute in the burden of lung diseases.(1) Many respiratory disorders including Asthma, COPD, Interstitial lung diseases and lung

'Financial or Other Competing Interest': None.

Submission 12-01-2018, Peer Review 06-02-2018,

Acceptance 12-02-2018, Published 19-02-2018.

Corresponding Author:

Dr. Santosh Kumar,

Department of Tuberculosis and Chest Diseases,

S. N. Medical College, Agra.

E-mail: skumardr2007@rediff.com

DOI: $10.14260 /$ jemds $/ 2018 / 228$

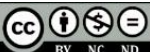

cancer may be caused by or exacerbated by factors in the work places Historically, pneumoconiosis has been the most commonly diagnosed occupational lung disease. Worldwide, silicosis remains the most common occupational lung disease.(2) Industries where silicosis was common included stone cutting, Quarrying, and rock blasting, construction and founding of ferrous and non-ferrous metals. Silicosis develops from the inhalation of silica particles in the lung parenchyma and the tissue reaction to it which is characterized by discrete nodular pulmonary fibrosis and as the disease progresses, by conglomerate fibrosis and respiratory impairment.(3) People suffering from silicosis are also at increased risk of other pulmonary diseases, such as bronchitis, tuberculosis and lung cancer.(4) 
The most frequently occurring pathologic effect of silica are multiple nodular lesions in lung parenchyma, bronchial associated lymphoid tissue, lymph nodes, and other viscera and fibrotic lesions of the pleura. Nodular lesions in the lungs may develop by conglomeration into larger lesions of progressive massive fibrosis.(5) Diagnostic approaches to the silica-related diseases are beyond the scope of this statement, but they are readily available elsewhere. $(6,7,8)$

Exposure to silica of respirable size occurs in mining quarrying, drilling, and tunnelling operations. Silica exposure is also a hazard to sandblasters, stonecutters, and pottery, foundry, ground silica, and refractory brick workers. Finely ground silica sand is used as an additive in many manufacturing processes. Abrasive blasting using silica sand or other silica containing materials has been found to be a particularly high-risk occupation. Clusters of new cases of silicosis in abrasive blasters continue to occur despite the development of respiratory protection more than $60 \mathrm{yr}$. ago, and silica sandblasting still carries high risk for excessive exposure to silica even when respiratory protection is used. $(1,2,9,10,11)$

In the present study we will evaluate the prediction of exercise capacity in apparently healthy Stone workers of Agra, who are engaged in handicraft industry by diffusion study.

\section{MATERIALS \& METHODS}

This is a descriptive comparative study, we evaluated 54 patients who were apparently healthy and had occupational history as stone workers, those were reaching the T.B. \& chest department, S.N. Medical College, Agra for evaluation, of age less than 75 years, interested in participating in our study filling into inclusion criteria, irrespective of present "smoking status" were enrolled into the study. Out of the 54 patients of stone workers evaluated, 24 patients were excluded from the study because 8 patients had past history of pulmonary tuberculosis, 2 patients had past history of pneumothorax, 2 patients had scoliosis, 3 patients had past history of pleural effusion, and 9 patients were unwilling to participate in the study.

\section{Design of Study}

This will be a descriptive comparative study between apparently healthy stone workers and unexposed healthy person of Agra region.

\section{Study Sample}

54 apparently healthy stone workers from Agra region who were in this industry at least for 5 years and attended our OPD in the duration of study period. Out of 54 patients 24 were ruled out as 9 patients did not give consent to participate in the study, 8 had past history of tuberculosis, 2 had scoliosis, 3 had past history of pleural effusion and 2 had past history of pneumothorax. So finally, 30 cases were included in the study as they fit into the inclusion criteria and having none of the exclusion criteria irrespective of sex, religion, cast, social-economic status, educational qualification and nationality were enrolled for this study. (This is how our sample size was decided)

Further 28 non-exposed healthy volunteers as control who were attendants of cases who came to the OPD along with the cases and were interested in participating in our study fitting into inclusion criteria and having none of exclusion criteria. Study Period- The study was conducted from September 2011 to May 2012 for a period of nine months.

\section{Inclusion Criteria}

- Apparently healthy stone workers who were engaged in this occupation at least for five years.

- Age less than 75 years.

- Control- who are not exposed to stone working.

\section{Exclusion Criteria}

- Past history of pulmonary tuberculosis and other lung diseases (Pleural effusion, pneumothorax etc.).

- Chest wall deformity and Neuromuscular disorders.

- Unwilling to participate in the study.

\section{Spirometry}

Spirometry measurements were undertaken in every patient those are engaged in stone industry for more than five years. Spirometry was performed by using techniques that meet published standards. Spirometry was performed on P.K. Morgan's Spiro 232 pulmonary system in pulmonary function lab of Department of T.B. \& Chest Diseases, S. N. Medical College, and Agra. PFT was performed on P. K. Morgan's machine in PFT Lab. The spirometer was calibrated regularly. Spirometry was performed using Techniques that meet published standards.(12)

\section{Pulse 0xymetry}

All the patients were screened by portable pulse oxymeter while breathing at room air after 30 minutes of complete rest.

\section{Six Minute Walk Test (6MWT)}

This is a timed walk test for objective evaluation of functional exercise capacity. This self-paced timed walk test assesses the sub maximal level of functional capacity. Because most activities of daily living are performed at sub maximal levels of exertions, the 6MWT may better reflect the functional exercise level for daily physical activity. Test was performed in a $30 \mathrm{M}$ long, flat, straight, enclosed hospital corridor with a hard surface that is seldom travelled.

\section{Diffusing Capacity for $\mathrm{O}_{2}\left(\mathrm{D}_{\mathrm{LO} 2}\right)$}

The diffusing capacity is calculated on the volume of gas absorbed by pulmonary blood per unit time (V) divided by the pressure gradient between alveolar gas $(\mathrm{P} \wedge)$ and capillary blood ( $\left.\mathrm{P}_{\text {cap }}\right)$ for $\mathrm{O} 2$

$$
\begin{aligned}
& \mathrm{D}_{\mathrm{LO2}}=\underline{\mathrm{V}}_{\mathrm{O} 2} \\
& \text { PAO2- } \mathrm{P}_{\text {cap } 02}
\end{aligned}
$$

Measurement of $\mathrm{D}_{\mathrm{LO} 2}$ is difficult because in addition to diffusion, oxygen transfer may be limited by other mechanism, such as ventilation perfusion mis-match and shunting.

Diffusion capacity for Carbon-mono-oxide ( $\left.\mathrm{D}_{\mathrm{LCO}}\right)$

CO provides an excellent alternative in measuring diffusing capacity because CO normally is present in minimal amount in blood and binds to haemoglobin in the same manner as oxygen. 
Diffusion capacity ( $\mathrm{D}_{L \mathrm{CO}}$ ) or transfer factor $\left(\mathrm{T}_{\mathrm{LCO}}\right)$ for $\mathrm{CO}$ is computed as follows$D_{L C O}=$ millimeters of $\mathrm{CO}$ taken up by capillary blood $/ \mathrm{min}$ Mean alveolar $P_{\mathrm{co}} \quad$ mean capillary $P_{\mathrm{co}}$

\section{Statistical Analysis}

The data was analysed using SPSS (Ver. 22) software. Unpaired Student $\mathrm{t}$ test was used wherever applicable. $\mathrm{p}<0.05$ is statistically significant. Mean and Standard deviation was calculated.

\section{RESULTS}

Distribution of cases and control according to the base line functional exercise capacity (six-minute walk distance)

\begin{tabular}{|c|c|c|}
\hline Group & $\begin{array}{c}\text { 6 Minute Walk Distance } \\
\text { (Mean } \pm \text { SD) }\end{array}$ & p value \\
\hline Cases $(n=30)$ & $528 \pm 43.5673$ & \multirow{2}{*}{0.0478} \\
\cline { 1 - 2 } Controls $(\mathrm{n}=28)$ & $541.38753 \pm 46799878$ & \\
\hline
\end{tabular}

There was statistically significant difference in functional exercise capacity as judged by six-minute walk distance (Mean \pm SD) $(p=0.0478)$ when the cases were compared with controls, at baseline.

\begin{tabular}{|c|c|c|}
\hline Group & DLCO (Mean \pm SD) & P value \\
\hline Case $(n=30)$ & $26.97 \pm 4.614$ & \multirow{2}{*}{0.03078} \\
\hline Control $(n=28)$ & $29.8943 \pm 4.7110$ & \\
\hline $\begin{array}{r}\text { Table 1. Distrib } \\
\text { diff }\end{array}$ & $\begin{array}{l}\text { of cases and contro } \\
\text { lung capacity (DLC }\end{array}$ & to \\
\hline
\end{tabular}

There was statistically significant difference between diffusion lung capacity (DLCO) (Mean \pm SD) ( $p$ value-0.030) when compared between cases and controls.

\begin{tabular}{|c|c|c|}
\hline Group & $\begin{array}{c}\mathbf{S P O}_{2} \text { (At Rest) } \\
\text { Mean } \pm \text { SD }\end{array}$ & $\begin{array}{c}\mathbf{S P O}_{2} \text { (After 6MWT) } \\
\text { Mean } \pm \text { SD }\end{array}$ \\
\hline Case $(\mathrm{n}=30)$ & $95.4 \pm 1.7538$ & $94.633 \pm 1.7710$ \\
\hline Control $(\mathrm{n}=28)$ & $96.3214 \pm 2.0914$ & $94.6421 \pm 1.4710$ \\
\hline Table 2. Arterial Oxygen saturation (SpO & (at rest) at \\
baseline and after $6 \mathbf{6 W T}$
\end{tabular}

The arterial oxygen saturation decreased (Mean \pm SD) 0.77 in apparently healthy patient after 6MWT similar decrease in $\mathrm{SaO} 2$ (at rest) (Mean $\pm \mathrm{SD}$ ) 1.68 was also noted in patients of control group.

\begin{tabular}{|c|c|c|c|c|}
\hline Group & $\begin{array}{c}\text { Respiratory } \\
\text { Rate (At rest) } \\
\text { Mean } \pm \text { SD }\end{array}$ & $\begin{array}{c}\text { P } \\
\text { value }\end{array}$ & $\begin{array}{c}\text { Respiratory Rate } \\
\text { (After 6MWT) } \\
\text { Mean } \pm \text { SD }\end{array}$ & $\begin{array}{c}\text { P } \\
\text { value }\end{array}$ \\
\hline $\begin{array}{c}\text { Case } \\
(\mathrm{n}=30)\end{array}$ & $20.133 \pm 2.5560$ & 0.1338 & $21.2666 \pm 2.3034$ & 0.4311 \\
\hline $\begin{array}{c}\text { Control } \\
(\mathrm{n}=28)\end{array}$ & $19.178 \pm 2.1951$ & $20.6785 \pm 3.2891$ & \\
\hline \multicolumn{3}{|c|}{ Table 3. Comparison of difference in respiratory rate at } \\
rest and respiratory rate after exercise \\
\hline
\end{tabular}

After 6MWT there was no significant change in respiratory rate (at rest) $(\mathrm{p}=0.1338)$ and respiratory rate (After exercise) from baseline $(\mathrm{p}=0.4311)$ when compared between cases and controls.

\section{RESULTS}

We found that there was decrease in DLCO in cases as compared to control and statistically it was significant $(\mathrm{p}=0.03078)$.

When we compare functional exercise capacity (6MWT) between case $(n=30)$ and control then there was decreasing trend in 6MWT values in cases as compare to control and statistically it was significant ( $\mathrm{p}=0.0478$ ).

We compared Arterial Oxygen saturation $\left(\mathrm{SPO}_{2}\right)$ between case $(n=30)$ and control $(n=28)$. When we found that there was decrease in SPO2 in cases as compared to control.

We compared respiratory rate between case $(n=30)$ and control $(n=28)$. Then we found that there was increase in respiratory rate after $6 \mathrm{MWT}$ although statistically it was not significant $(\mathrm{p}=0.4311)$.

\section{DISCUSSION}

To evaluate the beneficial effect of this study, we included 30 Stone workers those who had previous history of as Stone workers at least for 5 years as cases and 28 person those did not have any history of previous exposure in Stone (Silica exposure) Industry as control.

When we compared diffusion lung capacity (DLCO) between case $(n=30)$ and control $(n=28)$ Silicosis causes fibrosis and destruction in the lung that proves fatal in due course of time.(13) It is one of the world's oldest known diseases that continues to kill people in occupations where workers are exposed to respirable fine dust over a long period. In India, an estimated three million workers are exposed to silica in mines and in industries, such as stone cutting, silica milling, agate, slate pencil, etc.(14) Among these, the highest prevalence of silicosis is in the slate pencil industry $(54.5 \%)$ followed by workers in agate industries (38\%).(15) High mortality rates due to silicosis is especially true of unorganized sector,(16) probably because of comorbidities such as tuberculosis and malnutrition. However, studies on silicosis in the unorganized sector, especially in a setting like India, are scarce. In the unorganized sector, small stone polishing units that are based in the homes of workers do not fall under the purview of the factories act and are, therefore, not accessible for monitoring to regulatory authorities such as the factory inspectorate. In addition, since the work is done at home, primary workers and their family members are always at risk of silicosis due to the exposure to respirable dust.

Studies conducted earlier reveal that the concentration of respirable dust in these household industries is very high and contain more than $60 \%$ free silica in it. Besides high prevalence of silicosis among the workers engaged in this unorganized industry, non-occupationally exposed groups are also reported to have silicosis (6.8-11.8\%), silicotuberculosis (2.8-6.3\%), and tuberculosis (18.820.1\%).(17)

Pulmonary function studies in simple silicosis do not usually demonstrate functional impairment.(16) Yet, there is a trend toward restriction in total lung capacity and compliance as the extent of profusion of small rounded opacities increases. This is most clearly manifested as overt restriction in some workers with Progressive Massive Fibrosis. As the disease progresses reduction in compliance usually precedes the reduction in Vital capacity or forced 
Expiratory Flow Rate.(7,8) Few non-smoking, dust exposed workers with simple silicosis develop air flow abnormalities.

Not much work has been carried out regarding diffusion lung capacity (DLCO) and functional exercise capacity (6MWT) in apparently healthy stone workers in India, while the prevalence of the disease is high and increasing continuously. In view of this scenario, the present study was carried out to evaluate the beneficial effect of diffusion lung capacity (DLCO) and exercise tolerance test (6MWT) in apparently healthy stone workers. A total of 30 apparently healthy stone workers were included for the purpose of this study, those having history of as stone workers for more than 5 years, enrolled in case group. 28 persons were included in control group those did not have any history of (Silica exposure).

All the patients of mean age 28.76667 years, were properly matched with no significant difference with respect to age, sex, height, weight, BMI, spirometric parameters (DLCO) and baseline functional exercise capacity (6MWT), and baseline clinico-physiological parameters e.g. respiratory rates, when compared between the two groups. The present study evaluated the arterial oxygen saturation decreased (Mean \pm SD) 0.77 in apparently healthy patient after 6MWT similar decrease in $\mathrm{SpO}_{2}$ (at rest) (Mean $\left.\pm \mathrm{SD}\right) 1.68$ was also noted in patients of control group.

In present study when we compared case and control according to diffusion lung capacity then we found that there is decrease in DLCO in cases as compared to control. In present study when we compared functional exercise capacity between cases and control then we found that there is decrease in functional exercise capacity in cases as compared to control. In present study when we compared respiratory rate between case and control after 6MWT then we found that there is increase in respiratory rate in cases as compared to control.

\section{Limitation of the study}

Owing to the small sample size and the study being conducted in a single tertiary centre, the results of the study cannot be generalized for the entire population. Further large-scale studies are required.

\section{CONCLUSION}

The study shows that in apparently healthy cases of silica workers, the earliest indicator of disease is the reduction of DLCO. Also, the exercise capacity is significantly reduced in these patients. (Though spirometry was normal in more than half of these cases). These 2 parameters help in early disease identification and allow for prevention of exposure, stop disease progression and alter the final course of illness and decrease significant morbidity and possible mortality.

\section{ACKNOWLEDGEMENT}

We are thankful to entire staff of Department of Tuberculosis and Chest Diseases for their valuable co-operation.

\section{REFERENCES}

[1] Cote JE, Steel J. Work related lung disorders. Oxford: Blackwell Scientific Publications 1987: p. 436.
[2] Bailey WC, Brown M, Buechner HA, et al. Silicomycobacterial diseases in disease in sandblasters. Am Rev Respir Dis 1974;110(2):115-25.

[3] Ziskind M, Jones RN, Weill H. Silicosis. Am Rev Respir Dis 1976;113(5):643-65.

[4] Gamble JF, Hessel PA, Nicolich M. Relationship between silicosis and lung function. Scandinavian Journal of Work Environment and Health 2004;30(1):5-20.

[5] Abraham JL, Wiesenfeld SL. Two cases of fatal PMF in an ongoing epidemic of accelerated silicosis in oilfield sandblasters: lung pathology and mineralogy. Inhaled Particles VIII. Ann Occup Hyg (In press) 1997.

[6] Davis GS, Barber P, Schenker M, et al. Occupational and environmental repiratory diseas. St. Louis: Mosby 1996: p. 373-99.

[7] Weil H, Jones RN, Parkes WR. Silicosis and related disease. In: Parkes WR. edr. Occupational Lung disorders. $3^{\text {rd }}$ edn. London: Butterworth Heinemann 1994: p. 285-339.

[8] Fleming D, Maynard D, McKinney B, et al. Silicosis: clusters in sandblasters: Texas, and occupational surveillance for silicosis. MMWR CDC Surveill Summ 1990;39(25):433-7.

[9] Glinddmeyer HW, Hammad YY. Contributing factors to sandblasters' silicosis: inadequate respiratory protection equipment and standards. J Occup Med 1988;30(12):917-21.

[10] National Institute for Occupational Safety and Health, Centers for Disease Control and Prevention. 1996. Controlling exposures to crystalline silica in the construction industry. DHHS Publication no, (NIOSH) 96-112. (Available from Publications Dissemination, DSDTT, NIOSH, 4676 Columbia Parkway, Cincinnati, OH 45226).

[11] Nicaise R, Vereerstranten J, De Clereq F. This diffusion capacity at rest and during exercise in pneumoconiosis. Select Papers 1987;10:70-9.

[12] World Health Organization. Geneva: Fact Sheet on Silicosis: N 238, May 2008. http://www.who.int/ mediacentre/ factsheets/ fs238/en/ [last cited on 2009 Jan 20]

[13] National Institute of Occupational Health. Generation of database on occupational diseases (Achievements) Ahmedabad:

2009. http://www.icmr.nic.in/000004/achievements1.htm

[14] Saiyed HN, Tiwari RR. Occupational health research in India. Ind Health 2004;42(2):141-8.

[15] Kulkarni GK. Prevention and control of silicosis: a national challenge. Indian J Occup Environ Med 2007;11(3):95-6.

[16] Gamble JF, Hessel PA, Nicolich M. Relationship between silicosis and lung function. Scandinavian Journal of Work Envorinment and Health 2004;30(1):5-20.

[17] Cohen C, Fireman E, Ganor E, et al. Accelerated silicosis with mixed-dust pneumoconiosis in a hardmetal grinder. J Occup Environ Med 1999;41(6):480-5. 